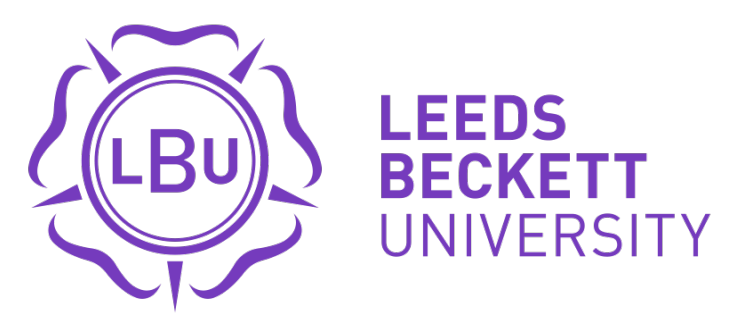

Citation:

Phoenix, C and Sparkes, AC (2006) Young athletic bodies and narrative maps of aging. Journal of Aging Studies, 20 (2). 107 - 121. ISSN 0890-4065 DOI: https://doi.org/10.1016/j.jaging.2005.06.002

Link to Leeds Beckett Repository record:

https://eprints.leedsbeckett.ac.uk/id/eprint/768/

Document Version:

Article (Accepted Version)

The aim of the Leeds Beckett Repository is to provide open access to our research, as required by funder policies and permitted by publishers and copyright law.

The Leeds Beckett repository holds a wide range of publications, each of which has been checked for copyright and the relevant embargo period has been applied by the Research Services team.

We operate on a standard take-down policy. If you are the author or publisher of an output and you would like it removed from the repository, please contact us and we will investigate on a case-by-case basis.

Each thesis in the repository has been cleared where necessary by the author for third party copyright. If you would like a thesis to be removed from the repository or believe there is an issue with copyright, please contact us on openaccess@leedsbeckett.ac.uk and we will investigate on a case-by-case basis. 
POST-PRINT

This full reference for this paper is:

Phoenix, C., \& Sparkes, A. C. (2006). Young athletic bodies and narrative maps of aging. Journal of Aging Studies, 20, 107-121

\title{
Young Athletic Bodies and Narrative Maps of Aging
}

By

\section{Cassandra Phoenix \& Andrew C. Sparkes}

\begin{abstract}
This paper draws on data generated by life history interviews with 22, university based, young athletes to explore their narrative maps of aging. Three key resources were seen to provide information that shaped individual stories of self-aging. These were as follows: family members, older team members, and the undergraduate curriculum. Each of these is considered in turn and the manner in which they are consequential in constructing a feared self that is associated with bodily decline in the future is highlighted. It is suggested that these young athletes constitute a vulnerable group in relation to the aging process. The issue of narrative foreclosure is then discussed prior to suggestions being made as to how these prevailing narrative maps might be challenged and changed.
\end{abstract}

Keywords: Age; Bodies; Narrative maps; Athletes; Possible selves

\section{Introduction}

Against a backdrop informed by the traditions of symbolic interactionism (Blumer, 1969), ethnomethodology (Garfinkel, 1967), social phenomenology (Schutz, 1970), the dramaturgical perspective of Goffman (1956), and certain stands within social constructionism (Gergen, 1999, 2001), various scholars have drawn attention to the different ways in which phenomena such as the self, gender, and age are interactionally accomplished or performed in social contexts (Birren, Kenyon, Ruth, Schroots, \& Svensson, 1996; Butler, 1990, 1993; Connell, 1995; Faircloth, 2003; Gubrium, Holstein, \& Buckholdt, 1994; Holstein \& Gubrium, 2000; West \& Zimmerman, 1987). Thus, according to Laz $(1998,2003)$, from a sociological perspective that seeks to integrate materialist-corporeal and constructivist-discursiverepresentational views of the body, age can be understood as something that is accomplished or performed. It is something that we do. For her, age is a phenomenon we (individually and collectively) work at making meaningful (in general and particular) through various interactions that are framed in the context of institutions and social structures.

Certainly, age may not always be equally salient or meaningful in the same way in all situations. However, it persists as part of the landscape of self, interaction, and institutions. Age, therefore, is not simply shaped by social forces; rather, Laz (2003) suggests, it is constituted in interaction and gains its meaning via interaction in the context of larger social forces. 
We accomplish age; we perform our own age constantly, but we also give meaning to other ages and to age in general in our actions and interactions, our beliefs and words and feelings, and our social policies... If the accomplishment of age is social and collective, then we need to attend to the social settings and contexts in which people 'act their age' and to the variety of resources that individuals draw on, use, and/or transform in the process of accomplishment. Some of these resources are widely available-for example, the law, media, and medical knowledge and practices... Others are narrower in scope-community standards and beliefs, local culture, and kinship networks. Yet, another cluster of resources is highly personal and potentially idiosyncratic-interpersonal relationships, physical bodies, and biographies. As we 'do age', we draw on this array of resources and make use of them in complex ways that are neither entirely random nor completely patterned or predictable (Laz, 2003, pp. 506507).

Importantly, Laz (2003) then proceeds to highlight the intimate connection between age and embodiment in terms of how they are accomplished and performed. For her, how one 'does age' has implications for corporeal existence and embodiment has implications for how one can accomplish age: "As we accomplish age, we draw on the physical resources of the body, but our actions and choices simultaneously shape the corporeal resources available" (p. 508). In making such connections, Laz draws attention to the historical 'absent-presence' of bodies in the social sciences in general and social gerontology in particular. In this regard, while Twigg (2004) notes that bodies have become of greater interest to sociologists in recent years she confirms, "their presence in social gerontology has been more muted and uncertain" (p. 59).

Stimulated by the work of Laz (2003) and her aspiration to contribute to the development of a theoretical and embodied sociological perspective on age, in this article we focus on a group of people that have been virtually ignored in the social gerontology literature, that is, young people who are athletes. Given the ways in which these young people inhabit and experience specific, and some might say spectacular kinds of bodies, we are interested in how this group conceptualize aging. In particular, we are interested in the various resources they draw upon to 'act their age' and how their current positioning within specific discourses and social forces shape their present beliefs about how they might experience different forms of embodiment and accomplish age in the future. To address these interests we have drawn upon the domain of narrative studies for methodological inspiration.

\section{Narrative maps, aging and embodiment}

As part of the 'narrative turn' within the social sciences, scholars have begun to treat seriously the view that people structure experience through stories and that they are essentially storytelling animals. This has led to a more sophisticated appreciation of people as active social beings and focused attention on the way personal and cultural realities are constructed through narrative and storytelling. Indeed, Somers (1994) suggests that social life is itself storied and that narrative is an ontological condition of social life:

Their [narratologists] research is showing us that stories guide action; that people construct identities (however multiple and changing) by locating themselves or being located within a repertoire of emplotted stories; that "experience" is constituted through narratives; that people make sense of what has happened and is happening to them by attempting to assemble or in some way to integrate these happenings within one or more narratives; and that people are guided to act in certain ways, and not 
others, on the basis of the projections, expectations, and memories derived from a multiplicity but ultimately limited repertoire of available social, public, and cultural

narratives (p. 614).

Qualitative researchers, in particular, have become increasingly interested in narrative forms of inquiry because, according to Polkinghorne (1995), narrative is the "linguistic form uniquely suited for displaying human existence as situated action. Narrative descriptions exhibit human activity as purposeful engagement in the world" (p. 5). For Crossley (2000), Cortazzi (1993), McAdams (1993), McLeod (1997), and Murray (2003) a story not only imparts information about the inner world of the storyteller or the person(s) about whom the story is being told but it also reveals a great deal about the identity, intentions, and feelings of the person telling the story.

Indeed, as Murray (2003) points out, narratives also provide a structure for our very sense of selfhood and identity, "We tell stories about our lives to ourselves and to others. As such we create a narrative identity" (pp. 115-116). Furthermore, Miller (1994) argues that personal stories on remembered and expected experiences are an important site for the social construction of self in which facets of self and various identities are projected and maintained over time. For her, selves like cultures "are not so much preserved in stories as they are created, reworked, and revised through participation in everyday narrative practices that are embedded in and responsive to shifting interpersonal conditions (pp. 175-176).

Importantly, therefore, a focus upon narratives of aging and embodiment can be used to explore both individual and group subjectivities. As Riessman (1993) notes, for the sociologically orientated investigator, studying narratives is useful for what they reveal about social life, in that culture speaks itself through an individual's story: "Narrators speak in terms that seem natural, but we can analyze how culturally and historically contingent these terms are" (p. 5). This is because, as Murray (1999) points out, "Narratives do not, as it were, spring form the minds of individuals but are social creations. We are born into a culture which has a ready stock of narratives which we appropriate and apply in our everyday social interaction" (p. 53).

Against this backdrop, it is interesting to note the recent emergence of narrative forms of inquiry within gerontology. Reflecting on this development, Birren (2001) notes that there is "something about the 21st century that is promoting a restlessness and sense of urgency while at the same time creating a desire to explore our internal views of life. Expressing this inward look is "narrative", the personal accounts of lives, the stories we tell about our lives" (p. vii).

According to Ruth and Kenyon (1996), using narrative approaches within gerontology is important for several reasons. For them, narrative provides an excellent medium for investigating both the similarities and differences of human aging over the life course. In part, this is achieved by revealing some of the complexities and contradictions that are embedded within the experiences of growing older, along with the construction of different selves and identities over the life course. Furthermore, Ruth and Kenyon propose that through employing a narrative approach to gerontology, researchers may be able to describe how cultures, subcultures or family patterns are reflected in the life of the storyteller and how certain people adapt to or expand the possibilities and limits set by the historical time period in which they live. Finally, these authors contend that narrative approaches are useful at a general level in generating theories and interpretations of development throughout the life course. Narratives 
are also central in facilitating an understanding of both personal and social aspects of aging as lives progress.

Emphasizing the social nature of narrative, various scholars (e.g. Bruner, 1990; Gergen, 1994; Gubrium \& Holstein, 1998; Holstein \& Gubrium, 2000; Linde, 1993; Mishler, 1999) have argued that any narrative as a form of communication is partly influenced by the cultural conventions of telling and the social context in which the telling and listening takes place. Accordingly, the stories that people tell about their lives should not be regarded as simple reflections of their actual experiences or a transparent window to their inner private self rendered visible through dialogue. Rather, people resort to a mode of telling with which they feel familiar. In this sense, narrative is a form of social practice in which individuals draw from a cultural repertoire of stories that they then assemble into personal stories. Consequently, in the very act of telling, people engage in creating and constructing certain kinds of body-self relationships in specific social contexts. In other words, it is through this social aspect of narratives that the dominant narratives available in a culture may act to shape not only who we think we are, but also who we think we can become in the future. Life and story are therefore connected and are always interlinked with the lives and stories of others in a relational manner. These others may operate to construct, deny, confirm, or problematize stories of the future in relation to aging and embodiment. They do so by offering those who have less knowledge of what lies ahead a narrative map of the future.

In defining a narrative map, Pollner and Stein (1996) point out, "Through passage to a new status or a new social world, persons may find themselves on the threshold of uncharted territory whose customs, contours, and inhabitants are unknown" (p. 203). They stress that in gaining purchase on an unfamiliar world beyond the horizon of the here and now, newcomers may seek knowledgeable or experienced others for orientation, information, and advice regarding the psychosocial and physical landscape that presumable awaits them in the future. In this sense, relationships with members of other generational groups can be significant in providing narrative maps that describe and advise new comers about the people, practices, and problems they are likely to encounter as they grow older. For example, in representing their experiences of aging and of inhabiting/living through different kinds of bodies, older people can provide younger people with pre-presentations of what is to come as they age and how they might experience different forms of embodiment.

Importantly, these pre-presentations or narrative maps may be consequential for how young people relate to the future. That is, stories can portray features of the aging process in positive or negative terms thereby contributing to socialization and social reproduction by confirming cultural stereotypes of aging and forms of embodiment or, alternatively, acting to challenge and problematize these stereotypes. Furthermore, these maps may also shape the actions of the young people who draw upon them by directing them toward certain areas and activities and away from others, and by specifying preparations in the present necessary for effective action in the future. As Pollner and Stein (1996) emphasize, by providing a preview of what is to come, narrative maps "may increase or reduce anxiety, motivation, and morale depending, of course, on what is portrayed as awaiting the traveller" (p. 219).

With the above points in mind, in what follows we explore the narrative maps drawn upon by a group of young athletes as they describe their futures as aging bodies. We believe that exploring their stories of self-aging is an important contribution to narrative gerontology. In part, this is because it has the potential to illuminate the significance of aging narratives within our culture in terms of their potential to shape and frame the ways in which growing old is 
perceived by different groups. Furthermore, such research also addresses a current gap in the social gerontology literature. That is, the majority of research to date has involved older individuals describing their current experiences of being old, or looking back over their lives. Few studies have considered the perspectives of young people looking forwards and expressing views on their own aging process and the different forms of embodiment they expect, hope, or are afraid to experience. Those studies that have touched on this issue (e.g. Fennell, 1994; Hyde \& Gibbs, 1993; Newman, Faux, \& Larimer, 1997; Scott, Minichiello, \& Browning, 1998), although clearly informative and important, have primarily discussed young peoples' attitude towards the elderly, rather than focusing on their own expectations of growing old. As such, stories of self-aging and embodiment over the life course as told by young people have been neglected. Consequently, despite our increasing understanding of older people's experiences of later life, to date we have little comprehension of the ways in which growing older may be anticipated by young people who exist through particular bodies such as athletic bodies.

A rare exception that does focus on young bodies is a phenomenological study by Adams-Price, Henley, and Hale (1998) that explored the meaning of aging for young (18 to 24 years) and old (over 65 years) adults. Young people in this study viewed aging as a negative experience, a conclusion further reinforced by reports involving British participants undertaken by Age Concern (1990), British Gas (1991), and Anderson, Duddleston, Lancaster, and Martin (2001). This rather pessimistic attitude towards aging displayed by young people has been attributed to a number of factors, many of which are related to the physical changes associated with an aging body. For example, Anderson et al. (2001) observed that for young participants, "Initial associations with age and aging tended to be pejorative, focusing on the narrowly physiological and often underpinned by images of physical decay, dependence and death" (p. 2). It would seem therefore, that changes to the physical body over the life course are a pertinent issue for the young. This may be particularly so for specific populations such as young athletes who are inclined to inhabit and engage with the world via particular kinds of 'high performance' bodies that have certain characteristics. For example, they tend to be highly disciplined and shaped by various regimes and technologies designed to ensure corporeal control and ensure predictable performance outcomes (Frank, 1991; Sparkes, 1998, 2004). Moreover, while the body is immediately relevant to the identity that any individual attempts to promote, it is to be expected that it will hold particular significance to the young athlete whose self-identity is constructed and maintained around possessing an able, pain free, physically fit, and performing body. Physical changes associated with the aging process, however, are likely to lead to an inevitable 'decline' in sports performance over time once an optimal age for a sport has been passed. As such, young, athletic bodies and the stories they tell can provide some interesting insights into the multiple ways in which self-aging is perceived.

In what follows we present an overview of a 3-year project designed to explore young athletes perceptions of self-aging. First, the methodology informing the project is outlined. Next, the narrative maps of aging principally drawn upon by young athletes when describing what might await them in the future are identified. Finally, the ways in which these narrative maps of aging operate to shape and frame future body-self relationships are considered.

\section{Methodology}

Phase one of this project involved 179 undergraduates $(\mathrm{m}=91, \mathrm{f}=88)$ enrolled upon a sport and exercise sciences degree course responding to a battery of questionnaires, which included the General Attitude to Ageing Scale (GAA: O'Hanlon \& Coleman, 2000, 2003) and the Athletic 
Identity Measurement Scale (AIMS: Brewer, Van Raalte, \& Linder, 1993). Using the results from these questionnaires, we were able to select those individuals who (a) defined themselves as competitive athletes (as opposed to exercisers) and (b) represented the highest and lowest tertiles in their scores for the GAA and AIMS. These individuals were used for further analysis (Phoenix, Faulkner, \& Sparkes, 2005), and to generate a purposeful sample for phase two.

Phase two of the study, the data on which this article is based, involved confidential, semistructured, life history interviews with 22 young athletes $(m=9, f=13)$ with a mean age of 20 years. The young athletes participated in either team $(n=15)$ or individual $(n=7)$ sports ranging from international $(n=7)$ to regional representation $(n=5)$ to at least university level $(n=10)$. Interviews were conducted in a purpose built facility on the university campus by the primary investigator [Cassandra Phoenix] who acted as an active and creative listener. As Wolcott (1994) explains, this involves taking an interactive role in making a more effective speaker out of the person talking so that they can tell their life story in their own way and in their own words. Thus, rather than adopt a distanced stance towards the participants an empathetic stance that displayed interest and openness was adopted throughout the interviews. Furthermore, in her role as learner in relation to their lives, the primary investigator encouraged the participants to elaborate on the meanings they ascribed to certain events and people so that she could better understand their views of self-aging.

Prior to the first interview, the ethical principles that would inform the process were discussed with each participant. These included the following: the content of the interviews would be confidential; the interviews would be audio-taped and the only person to listen to the audiotapes and transcribe them would be the primary investigator. It would be the participant's decision at the end of the project as to whether the audiotapes were returned to him or her, wiped clean by the primary investigator, or were allowed to remain in her possession for further analysis. It was agreed that in any publications pseudonyms would be used to protect the identity of those involved. It was also made clear to the participants that they were free to terminate an individual interview or withdraw from the study completely without having to provide any explanation for doing so.

Participants were interviewed between one and three times, with each interview lasting between 1 and $2 \mathrm{~h}$. The total hours interviewed were fifty five and three quarter. All interviews were audio-taped. After each interview, the primary investigator transcribed the tape verbatim and then assumed the posture of indwelling (Glense \& Peshkin, 1992). This entailed reading through the transcript several times in order to immerse herself in the data and understand the participant's point of view from an empathetic rather than a sympathetic position. Next, the transcript was read through again several times with a view to identifying narrative segments and categories within it. As part of this process analytical memos were also made. Following this, in discussion with Andrew Sparkes in his role as 'critical friend', preliminary and tentative connections were made to theoretical concepts related to issues emerging within each participant's story. This process along with the analytical memos helped shape the questions asked and the themes explored at the next interview as part of a cyclical process. As the interviews progressed and data were accumulated, connections were sought across narrative segments and themes in an attempt to identify patterns and meanings constructed both within and between the stories told by the participants in order to facilitate a comparative analysis of their narrative maps of aging. This process is similar to the categorical-content analysis described by Lieblich, Tuval- Mashiach, and Zilber (1998) that focuses upon the thematic similarities and differences between the narratives generated during interview situations. 
The analysis revealed that in constructing stories of self-aging, the young athletes involved in this study looked to older and experienced others for information and advice concerning the aging process. In particular, three inter-related resources were drawn upon to shape the narrative mapping process. These were, family members, older team members, and the curriculum of their degree course. These will now be discussed in turn.

\section{Family members}

According to Hockey and James (2003), the family is traditionally regarded as the primary site of socialization, and can be seen as one of the key contexts within which people come to know who they are as they age. In addition, it would seem that through the family, young people construct ideas relating to who they will be in the future. Supporting this, the data from the present study indicate that the family is significant for providing information and advice to young athletes with regards to growing up and growing old. The following comments from Louisa (age 21, university level hockey) illustrate this point:

Interviewer: Where do you think we learn about growing old?

Louisa: By looking at our parents and grandparents and those that are close to us, and seeing what they look like, you kind of build up perceptions of how you will look. Parents, I think, a great deal because everyone says I look like my mum so I see her now and I think, 'I could look like her when I'm older'.

Importantly, for the young athletes involved in this study, the family was not viewed as a homogeneous site of storytelling and socialization. Parents provided narrative maps relating to middle age while grandparents offered information pertaining to old age. For example, Pamela (age 20, university level swimming) referred extensively to her parents' experiences when asked what signs she would use to indicate that she was growing older.

Probably physically the signs would be the strongest. I know it bothers my dad, the fact that he's getting older because he used to be in the army and would do a lot of lifting of weights and stuff. His back is now not good at all and that really, really, bothers him. I can see it bothering my mum as well but more in respect of going grey and wrinkly, whereas my dad I think it bothers him that he's not as physical as he used to be. But yes, it would probably be physical signs that I'd look for. In addition, describing his anticipated physical activity levels in middle age, Neil (age 21, university level hockey) made the following comment:

I'm kind of using dad as an example but I can see me generally not doing too much physical activity during the week, maybe play something like squash or badminton one or two nights a week and then at the weekend doing the majority of my activity then. Like hopefully still playing hockey and probably umpire or coach or something like that. But not nearly as much as now. The reason for that is probably a combination of being less physically able to do that, and also just the time constraints. At the moment I've got time to train everyday and as much as I want. But yeah, I look at my parents and I see that the majority of their activity is done at the weekends. So I can see during the week that I won't be doing much at all, and then at weekends trying to do as much as possible. I'm not looking forwards to it, particularly not being able to train whenever I want to, and then of course there's always the risk of putting on weight, getting unfit, you know...

The comments from Louisa, Pamela and Neil illustrate how the young athlete's perceptions of self-aging are shaped by the narrative maps provided by their parents. They also demonstrate 
how these maps of middle-age are intimately linked to the corporeality of the gendered body that is fore-grounded in descriptions of the aging process. Here, aging fathers seem to offer performance related scripts that revolve around concerns over the gradual reduction in control of a previously self-regimented, disciplined, pain-free, forceful, and youthful body. This narrative map depicts growing older in terms of performance loss associated with the demise of the disciplined body.

According to Frank (1991) this kind of body seeks to make its performances predictable though following specific regimes. As an example, one has only to think of the highly technical training regimes that elite athletes subject themselves to from an early age in order to produce predictable performances. The most important action problems for this kind of body are about control and, not surprisingly, it experiences its most serious crisis in loss of control. As a consequence, narrative maps of aging that signal this loss of control in future years are likely to be anxiety provoking for both male and female young athletes alike.

In contrast to fathers, mothers provided narrative maps for the young athletes that focused primarily upon aesthetic concerns relating to body shape and the appearance of its surface. Here, as the female body ages it is seen to move further away from the Western ideal of prescribed femininity as youthful, trim, firm and sensual (Bordo, 1993). While the narrative map provided by the mothers did project a decline in the disciplined body in performance terms, it also emphasized the loss of control in terms of appearance. Hence, this process of mapping is linked to the mirroring body. Frank (1991) describes this body type as being associated with itself, or rather, with its own surface in such a way that the primary sense is visual.

Beyond narrative maps of middle-age provided by parents, the grandparents were defined as a key resource for understanding how life is experienced in and through an 'old' body. For example, echoing the other young athletes, Pauline (age 20, university level pentathlon) had difficulty visualizing her own body as old. Accordingly, she drew from a narrative map provided by her grandmother in order to gain some purchase on how her own older body might look and feel in the distant future.

I just can't imagine, sort of imagine it. I see photos of my nan when she was like twenty or whatever, and the change and just the appearance, it's amazing. It's just so different, you'd hardly know it was the same person kind of thing. Now, she's like really tiny and she hasn't got like any muscle on her or anything even though she eats well and she's as active as she can be I suppose.... She's changed so much...like her hair going grey and losing muscle and things, and having problems being able to get around. It's quite scary.

The comment by Pauline relates to a number of physical changes her grandmother has encountered since being 'twenty something'. Crucially, these changes are indicated by the physical body in terms of how it looks and moves such as, going grey, losing muscle, and becoming increasingly immobile. This projection, based on a visual assessment of one person, leads Pauline, like many of the other young athletes to perceive old age as 'scary'. The impact of anticipated age related physical changes on young athlete's perceptions of self-aging is also illustrated in the following comment by Gary (age 20, university level rugby):

Interviewer: How do you feel about being old?

Gary: I don't, I'm not really looking forwards to it. 
Interviewer: What makes you not look forwards to it?

Gary: I don't know ... I'm sure if I did have a really nice wife and grandkids, I'm sure it must be quite nice to do that and not do any work and all of that. But, then I see my nan and grandad because they only live around the corner from us and I've been around their house everyday since I was nothing. My grandad can't really move much out of his chair now, his legs are gone, he's got terrible arthritis and my nan is finding it really hard to look after him. And I just think that is not a very nice thing to have like... that might happen to me. I suppose I don't look forwards to it because of what I have seen with my grandparents.

The comments above indicate that the narrative maps provided by grandparents are central in terms of how the young athletes conceptualize old age, and how these maps often feature and fore-ground notions of a declining and deteriorating body that lives with pain, weakness and limited mobility. Not surprisingly, given their current physical status and substantial investment in a sport performing body-self, the young athletes viewed the prospect of old age with trepidation and anxiety.

\section{older team members}

For the young athletes, older team members were also seen as a source of information and advice relating specifically to the aging body in the context of sport. For example, when Neil (age 21, national level hockey) was asked what the term 'growing old' meant to him, like many other participants his response referred to experiences of known older team members.

Growing old... stuff like becoming less physically fit and, I don't think the kind of intellect, that sort of stuff doesn't really come to mind straight away for me. It's more the physical things, like getting fatter, being less able to play a high level of hockey and go for runs, getting injured more often and stuff like that. A decrease in mental stuff, I can't really imagine it as much. I can just see me being this level of intellect the whole time, whereas my body will actually kind of worsen... Specifically for hockey, I think of sharpness, just sprinting off the mark. Like sharpness of skills and stuff like that, I can see them kind of worsening. I think that's partly because I've played with older players and people say to you 'He used to be a really good player in his time'. And you can see from their movement that they've got the right actions, but it's all a little bit slower. You can tell that they obviously were a good player, but everything is a little bit slower and a little bit less sharp. I think that I can probably see that happening, just everything getting a little less kind of co-ordinated and, just everything being slower.

Such comments demonstrate how young athletes draw upon embodied experiences relating to the past and present performances of older team members when storying their own sporting bodies in the future. Importantly, these particular narrative maps portray growing old primarily in terms of physical deterioration, and a subsequent loss of the disciplined body. That is, when gathering information relating to the aging process, young athletes witnessed older team members losing control of a body that had once been fast and predictable in its physical capabilities. Nick (age 21, national level hockey) reinforced this view when he was asked whether he thought older team members ever felt awkward around the younger players.

Oh definitely. I mean talking to some of the older guys after the game and they'll say, 'I woke up the next day and I was so bloody stiff, my body's aging.' Or we'll be doing a training session and someone will say to them 'Come on, speed up old boy,' or 
something like that and they'll say 'Bugger off. I'm thirty-five years old, you're twenty.' So I think they definitely do get a bit paranoid about their age and their fitness and their speed, things like that. It must be quite hard for them.

As suggested above, the content of ostensibly 'friendly banter' made by young team members, along with comments made by the older team members themselves, are incorporated into the narrative maps that are then circulated within the sporting subculture, as stories of self-aging are constructed in relation to particular performing body-selves.

\section{The exercise and sport sciences curriculum}

The curriculum of their exercise and sport sciences degree program was identified as the third key resource used by young athletes in developing their stories of self-aging. The ways in which curriculum content helped shape the narrative maps of the young athletes are illustrated in the following comments. First is Laura (age 21, university level basketball) explaining how her degree course has influenced her views about aging.

I think it's probably the sport sciences degree course that makes me have half of these attitudes about growing old, just because we have concentrated so much on fitness levels, and all this. You learn about what happens when you get to a certain age and your fitness goes 'vroom' [indicates downwards trajectory with her hand], and like diseases and stuff that you can get, and how much more you are susceptible to injuries.

Likewise, Vicky (age 19, university level hockey) commented:

I think without even realizing it, coming here and doing sport sciences, has changed the way that I view my body and it's changed the way that I view aging. Like I think I used to view aging as being quite a positive thing... Although I still do see it as positive, I think being in a sport environment, playing sport, doing a sport science course it's almost why I'm having the thoughts I have now about body image and stuff. I think I worry more now than I ever would have done before. And maybe just because it's so... it's in your face, you think about it more, maybe that's why I think about it more, I worry about growing old more.

Importantly, the information and advice offered by the degree program relating to old age was limited. That is, as a narrative map of aging the curriculum content focused almost exclusively on the functional and performance changes associated with the body over time, along with the role of physical activity in maintaining or managing the body throughout the life course. This had implications for the ways in which the participants viewed the aging process in general, their own expectations of being involved in it, and the role of exercise in this process. Typically, aging was defined as the problem, and exercise was deemed to be a solution (Eichberg, 2000).1 That is, exercise regimes of various kinds were often interpreted as a means of maintaining or regaining control over a disciplined body that was expected to become increasingly unruly over time. For example, similar to other participants, when describing where he learnt about growing old John (age 19, national level hockey) made reference to particular modules within his degree program. These modules reinforced the notion of using exercise to invest in and maintain the body over the life course.

I think with modules like 'Public Health,' you learn about the exercise that you're doing now. You'll have the benefits when you're older in terms of heart problems, 
hypertension, osteoporosis, obesity, and things like that. It's like exercise now, and you'll benefit later.

Such comments indicate how the narrative map of aging provided by their degree program reinforced the notion of 'control' by suggesting a causal relationship between exercise, health, functional capacity, and appearance in later life. It would appear that via lectures, seminars, laboratory sessions and the directed reading of specific texts, the curriculum content acts as a 'scientific' and high status resource that provides certain measurable 'facts' about the aging process that are then incorporated into the narrative maps of the young athletes.

As indicated above, the curriculum content of their degree programme, along with information gathered from family members and older team members combine to act as resources for the narrative maps of the young athletes. Importantly, each of these resources has a tendency to emplot a story of decline with regard to the aging process, this being particularly so in relation to old age. As such, they provide a limited narrative resource for the development of possible selves in the future while simultaneously raising the spectre of feared selves to come.

\section{The future and possible selves}

According to Markus and Nurius (1986), possible selves represent individual's ideas of what they might become, what they would like to become, and what they are afraid of becoming. These authors point out that possible selves are important because they function as incentives for future behavior by representing selves to be approached or avoided. They also provide an evaluative and interpretive context for the current view of the self and are, therefore, relevant to how individuals think about their potential and their future. Possible selves are both personalized and distinctly socialin that they are the direct result of previous social comparisons. Here, the individual's opinions, feelings, attributes and behaviors are compared to those of salient others: "What others are now, I could become" (p. 954). As such, they are intimately connected to and shaped by the narrative maps made available to individuals and groups within specific cultural settings.

The narrative maps of aging made available to the young athletes, as evident in their perceptions of self-aging, suggest that their preferred and feared selves are primarily connected to the material condition of the physical body over the life course. For example, Louisa (age 21, university level hockey) like many of the participants, expresses how she would, and would not like to be in her old age, and what she would prefer and fear to be in the future.

I'd like to still be joined to a gym, or still be swimming or something because I really do enjoy sport... I'd like to be active. I'd like to be as young as I am now I suppose at that age, but I don't know. I'd like to think that I could always do something for myself, that I didn't have to rely on other people to do day-to-day stuff, because I think that must be the worst thing, realizing that you can't physically do everything for yourself ... I don't want to be waited on hand and foot, but I know that it comes to an age where you just have to rely on other people because you can't physically do it. I suppose at that age, when your body can't do anything because you're really frail and really, really old, it's kind of, it sounds horrible, but it's like waiting to die kind of thing. Especially if you're on your own and there's no one else around. If you're just lonely, I think it would be so 
much worse because you'd have nothing to aim for. You've finished your life ... Old age, that's quite a scary thought.

While all of the participants acknowledged the limitations of age-related physical changes, their preferred selves continued to represent a body that remains active, able, and independent. They recognized, however, that this might be problematic if this particular body type cannot be achieved. Against this, a number of feared selves were described that were associated with the loss of predictability over a body that had previously been controlled and disciplined in performance terms. Here, the body was dependent on others, inactive, leaky, painful, and weak. Greg (age 27, national level rugby) illustrated this when describing his thoughts on being old:

Hopefully it [my body] would still be working as it does sort of now... I'd still like to have control of all of my faculties and stuff... I think the biggest concern for me would be not being able to control my faculties. Like I could go to the toilet myself. I wouldn't need somebody to look after me or I wouldn't need to be fed or anything like that. I mean, I'm not worried say, if you need someone to come up and help you do something like dig a hole in the garden. My main worry is to be dependent on someone because I'm so independent now. I'm fit and strong. My worry would be to lose all control of that, to lose control of the body, which you used to have control over really. That would be my biggest concern. I wouldn't really want to rely on people in that way.

The feared self is also linked to notions of the mirroring body as described by Frank (1991). This was particularly the case for the young female athletes and signals the gendered dimensions of this process. For example, as observable features of the surface of the body, 'saggy skin', 'wrinkles', and 'weight gain', stand in opposition to the idealized, homogenized and normalized feminine form constructed within Western consumer cultures that is young, slim, taught and toned (Bordo, 1993; Öberg, 2003). In this regard, it is interesting to note the visual markers of age selected by the following two female participants. First, Heather (age 20, university level football):

Interviewer: What do you think that you'll look like in old age?

Heather: Dentures or false teeth and a hearing aid, thick glasses, thin hair, saggy body, I don't know, something like that.

Interviewer: What do you mean by 'saggy'?

Heather: Skin, like sags of skin and not tight...

Similarly, when asked the same question Louisa (age 21, university level hockey) remarked:

Louisa: (curls lip) that's a horrible thought.

Interviewer: Why is it so horrible?

Louisa: Because it's the kind of thing you've never really thought about before. I don't know, probably grey, probably slightly frailer because you do as you get older. Um... I don't know, probably grey, fairly wrinkly and kind of... (5 s silence) not clean cut, but like, do you know what I mean? I don't know how to describe it but kind of you know, definitely wrinkly, saggy.

Interviewer: Could you tell me what you mean by ‘saggy’? 
Louisa: Well, kind of as you get older, everything sags doesn't it. Especially with women, kind of under the arm and stuff.

These comments suggest that for the young athletes, notions of 'decline' and 'loss' permeate their narrative maps of aging in relation to their current youthful and athletic bodies. Accordingly, a number of feared selves await them that are associated with perceived bodily changes in middle and old age. These are summarized in Table 1.

\begin{tabular}{ll}
\hline Table 1 & \\
\hline Expected body changes in middle and old age & \\
\hline Middle age & Old age \\
\hline -Less physically active (too busy) & -Less physically active (physically restricted) \\
-Decreases in co-ordination & $\bullet$ Weak \\
-Decreases in agility & $\bullet$ In pain \\
-Decreases in speed & $\bullet$ III \\
-Decreases in strength & $\bullet$ Increases in recovery time from illness \\
-Increases in recovery time from exercise & $\bullet$ Unpredictable \\
-Increases in (likelihood of) injury & -Dependent \\
-In pain & -Leaky \\
\hline Loss of the performing body & $\bullet$ Slow \\
\hline
\end{tabular}

\section{Discussion}

The evidence presented in this article provides support for the assertion by Laz (2003) that despite it not always being equally salient or meaningful in the same way in all situations, age is anticipated as part of the landscape of the self, interaction, and institutions. Importantly, this includes the landscape that emerges in an interview setting. Accordingly, the stories told by the young athletes involved a reciprocal event between them and the primary investigator. Here, in telling their stories in a certain way, the athletes performed their preferred age-related identities during the interview (Langellier, 2001). According to Riessman (2002), to emphasize the performative element "is not to suggest that identities are inauthentic, but only that they are situated and accomplished in social interaction" (p. 701). As such, she argues, an essential self is not revealed. Rather, a preferred one is performed, "selected from the multiplicity of selves or personas that individuals switch among as they go about their lives" (p. 701).

With regard to the performance of age-related identities during interview, the data confirms the view of Laz (2003) that in accomplishing age, be it now or in the future, people draw on a variety of resources in order to engage meaningfully with this complex process in ways that are neither entirely random nor completely patterned or predictable as they develop narrative maps of what is to come. In this regard, a number of images, visions or plots of aging are available inWestern consumer cultures. For example, Öberg (2003) notes how aging bodies are often defined as 'problem' bodies in ways that perpetuate the 'misery' perspective on aging. In contrast, he points to the new images of older people that have emerged in popular culture where they "are looking and dressing youthfully, having sex, dieting, actively traveling, and so forth" (p. 103). Öberg highlights how for people in middle age, a new midlife is presented as a chance for self-realization and personal growth where an endless 'middle youth' as defined by Featherstone and Hepworth (1991) can be enjoyed. From this perspective, Öberg (2003) argues that aging becomes part of a personal project of the self that involves the 'agentic' construction of identities, "We can now, through the consumption of lifestyles, realize different 'possible selves' and actively determine how to be old: what to wear, where to live, how to look, and so on" (p. 110). 
Certainly as Featherstone and Hepworth (1995) acknowledge in their case study of how images of positive aging operate in a magazine geared toward people of retirement age, this perspective is not without its own contradictions and tensions (also see Tulle-Winton, 2000). For example, they note that the 'aging industry' was an important force behind the popular images of positive aging, and this was fuelled by a growing sensitivity on the part of merchandizers of the potential new markets in middle and later life. Likewise, they suggest that the new consumer-orientated positive imagery inevitably raises the question of the relevance of this imagery for the majority of the population in a society characterized by enormous inequalities in income and opportunity. Setting these concerns, and others, aside momentarily, it remains that notions of positive aging do offer a different narrative map to that of the decline and misery perspective. As such, the lack of reference by the young athletes in our study to aspects of positive aging is a noticeable absence. This is particularly so given that the dominant image of the body with regard to positive aging is that of a "machine that can be serviced and repaired, and the array of products and techniques advertised, cultivate the hope that the period of active life can be extended and controlled into a future where ultimately even death can be mastered" (Featherstone and Hepworth, 1995, p. 44). Since the 'body as machine' is a core metaphor within sporting cultures, and because this links into the demands and desires of the disciplined body for controlled performance outcomes, it remains strange that this narrative map was not called on by the young athletes in our study.

The lack of reference to positive images of aging is open to various explanations that lie beyond the remit of the data presented in this article. However, we might speculate that the young athletes in our study are not aware of this perspective or of other more favorable narratives of aging. Alternatively, they might be aware of images of positive aging but they choose to ignore its associated meaning structure and plot line in constructing their current narrative maps of what the future might hold for them. It could also be, given the preponderance of gerontophobic images that surround them concerning youthful performances and selfrepresentations, and given the kind of bodies they currently inhabit and experience the world through, that the decline narrative has greater personal relevance and meaning to them than other available narratives.

In this regard it is interesting to note Frank's (1995) suggestion that in telling a story about bodily experience there is

a sense in which the body creates the person. That is, when people tell stories about their bodies, the actual body gives the story a particular shape and direction. Thus, the story told reflects strong cultural and personal preferences, and different kinds of bodies seem to be drawn to, or propelled toward, stories of a particular kind. As Frank notes, different bodies have 'elective affinities' to different kinds of narrative, "These elective affinities are not deterministic. Bodies are realized-not just represented but created-in the stories they tell" (p. 52). As such, the young athletes in our study, living in and through particular kinds of disciplined and mirroring bodies, might have an elective affinity for a decline narrative with regard to aging.

In part, this elective affinity for the decline narrative can be linked to the manner in which their body-self relationships and their habitus have been developed over the years in relation to sports performance and the disciplinary practices utilized to achieve successful performance outcomes. As part of this process a strong athletic identity (the degree to which an individual identifies with the athlete role) is constructed that leads the individual to interpret any given event in terms of its implications for that individuals athletic functioning (Brewer et al., 1993; 
Lavalle, Grove, \& Ford, 1998; Sparkes, 1996, 1998). Some benefits of a strong athletic identity include the development of a salient self-identity or sense of self, positive effects on athletic performance, and a greater likelihood of long-term involvement in exercise behaviors. In contrast, there are potential risks for individuals with a strong athletic identity that relate to the difficulties they might encounter in career transitions such as reaching the end of a playing career, a transition that is directly associated with age. Individuals with a strong athletic identity are thought to be at risk of emotional disturbance in such transitions because they are less likely to explore other career, education, and lifestyle options due to their intensive involvement in and commitment to sport. Such role engulfment and premature identity foreclosure can create conditions that lead to a crisis for the athlete on retirement.

Given that performance tends to decrease with age in high level and elite sport, and given the relatively short span of a sporting career in relation to other occupations, it is perhaps understandable that the young athletes in our study are drawn to the decline narrative and focus their attention on the visible and embodied signs of this decline in those significant others who mirror to them what the future might hold for their own bodies in performance terms. This is particularly so when their undergraduate curriculum encourages them to understand their one corporeality and the corporeality of others as they age in biomedical terms rather than within a more social and relational context (Tulle- Winton, 2000).

Given the elective affinity of the young athletes in our study for the decline narrative of aging and its associated negative stereotypes of middle and old age, and given their substantial emotional investment in a young, fit, pain-free, able, strong, fast, performing body that sustains a strong athletic identity, their thoughts about aging are, perhaps not surprisingly, infused with feelings of anxiety and foreboding. The narrative maps constructed by them, therefore, invoke a number of feared selves. Of course, it could be argued that these young athletes are no different from those young people described by Öberg (2003) who do not look forward to growing old and who express worries about bodily changes in the future. Likewise, as Neikrug (2003) comments, "Worry about the loss of youth and the advance of years plagues many persons who are chronologically distant from old age" (p. 327). However, Neikrug goes on to state that the professional athlete and others who depend on the characteristics of youth for their livelihood may become 'old' long before they reach middle age. In one sense, therefore, it may be that for young athletes in our study the embodied 'fall from grace' as they age is likely to be greater and more intensely felt than for those who inhabit different kinds of bodies in their youth. As such, the young athletes may be very vulnerable to the 'negative' physical effects of aging on their senses of self as a performer. Furthermore, as Neikrug (2003) argues, "For younger individuals, internalized negative stereotypes of aging can support ageist attitudes, affect their relationships with older persons in their lives as well as causing worry about their own future" (p. 327). This is particularly so given the sense of narrative foreclosure that infuses the young athlete's descriptions of self-aging. Here, the later chapters to one's life are already known, the future appears to be a foregone conclusion, and one is destined to live out a story with a pre-scripted ending.

According to Freeman (2003), narrative foreclosure relates to the degree to which the culture in which one lives fails to provide adequate narrative resources for living one's life meaningfully and productively. Speaking of aging in Western cultures he notes that "with prescripted narratives of decline well in place, there often appears little choice among the aged but to reconcile themselves to their narrative fate" (p. 81). As such, narrative foreclosure is an eminently social phenomenon that connects to the reification of cultural storylines and the tendency, on the part of many, "to internalize the storylines in such a way as to severely 
constrict their own field of narrative expression: the story goes this way, not that" (p. 83). Therefore, Freeman argues, by accepting the prevailing endings to cultural stories one accepts a certain kind of narrative fate and this potentially reduces the possibility of self-renewal as one grows older. As Neikrug (2003) comments, "Worrying about a sad future possibly prevents the development of strategies necessary to create a positive and satisfying future world. In other words, an optimistic attitude toward what old age will be like may be an important variable in creating a successful old age" (p. 327).

Clearly, even though many of the young athletes in our study know, or believe they know what lies ahead through the narrative maps of aging offered to them by their family, older team members, and the curriculum of their undergraduate degree program, and older team members, this does not determine how they will experience their bodies as they age. That is, youthful imaginings about the future do not necessarily become an iron cage that contains the future before it is lived. How young people in their early twenties think they will experience their bodies in later life does not mean that this will be how they actually experience their bodies as they age. Indeed, this is an empirical question that warrants a longitudinal study of the young athletes to explore how they experience their bodies as they go through various stages in the life course.

Having rejected notions of determinism, it is important to recognize that the narrative foreclosure provided by their maps may have implications for the self-renewal of the young athletes in the future. Accordingly, we would suggest, it might be appropriate to provide them with opportunities to challenge and change the contours of the narrative maps that they currently hold. This is no easy task and Freeman (2003) acknowledges the difficulties of 'reopening' a foreclosed narrative of the sort provided by the young athletes.

In order to break the stronghold of narrative foreclosure and challenge its already 'known' ending, Freeman (2003) suggests it is necessary to rewrite or re-imagine the past. This involves the difficult step of becoming aware of the storylines one has internalized over the years. For the young athletes involved in our study, in the first instance, this would entail them being given assistance to actually recognize the contours and topography of the narrative maps they have internalized about aging from various sources and the manner in which this has shaped their definition of this process in terms of decline and loss. This done, the problematic nature of narrative foreclosure, such as its inherent selfdeterminism, can be identified and other possible endings opened up for discussion. That is, in Freeman's terms the process of desocialization can begin that "essentially involves identifying, becoming conscious of, the ways in which one has been constructed as a social agent and a carrier of culture. This process is at one and the same time a process of reconstruction as well, of rewriting the past and thereby achieving some measure of self-renewal" (pp. 90-91).

Similar sentiments are also offered by Gare (2001) who draws attention to the potential of viewing lives as being constituted through narrative. Indeed, understanding our lives as narrative may enable us to appreciate how personal narratives are related to the broader narrative maps shaped by families, organisations such as sport, and institutions such as universities. With this, an appreciation for what kinds of narratives people have been socialized into and what kinds of narratives could replace or accompany them may be achieved thereby potentially allowing a more meaningful future to be envisaged.

Part of the process of desocialization noted by Freeman (2003) involves re-imagining and rewriting the future so that the chains of the present can loosen their hold on the future. This would require expanding the narrative resources of the young athletes by making available 
different images and stories of aging that illustrate a range of different ways of emplotting movement through the life course. At one level this might involve contrasting the dominant plot lines of Western narratives of aging with other cultures. For example, the Japanese tradition involves a life curve, a ' $u$ ' that turns the Western model of the life curve, an ' $n$ ', upside down. One might also compare the wheel or circle of life that is prevalent in India, as well as considering shamanic shifts of the track, in relation to Western ideals of aging. As Eichberg (2000) notes, such comparisons are useful in allowing each model to criticize the other by revealing the socially constructed nature of each as one possibility of representing and understanding the aging process.

Alongside the cultural or structural approach described above, individual stories in the form of published autobiographical work by athletes that includes the dimension of aging could be incorporated into the curriculum. Such stories would provide more immediate access to the subjectivities involved and provide a range of perspectives on the aging athletic body. Here, for example, the autobiographical accounts by Sparkes (1996, 2003a, 2003b) of his impaired and aging athletic body that has led him to reconstruct a sense of self in positive terms could be used to challenge the prevailing narrative map of decline held by the young athletes. Similarly, former athletes who have not succumbed to the decline model and have redefined their aging in positive terms could share their stories and experiences with the young athletes. Here, it is interesting to note the suggestion of Neikrug (2003) that post-retirement persons would make very good 'retirement mentors' in retirement preparation programs for those groups who are most highly worried about this transition: "They could provide colleagues and previous coworkers information regarding their real life experiences and present a realistic picture regarding the nature of retirement" (p. 332). Similarly, former athletes could act as 'aging mentors' for young athletes by providing a range of experiences associated with the aging sporting body.

Following on from this, the young athletes could be encouraged to produce their own life stories to act as an analytic resource for use in a collaborative venture to reflect on their own and their peer's view of aging, how they are shaped by various resources, and how they might be changed so that the future is approached differently if this is defined as a desirable outcome. In this regard it is interesting to note the efforts of Altpeter (2003) who, having become aware of student disinterest in the topic of aging in general, and their own aging in particular, developed an undergraduate introductory module to be implemented across campus entitled "Introduction to aging". The course took a broad brush approach in covering the biological, sociological, psychological and political issues of aging, attended to students attitudes about the aged, the aging process, and also students views regarding their own aging. Similarly, Rich (2004) suggests a number of possible methods that we believe might assist students in becoming more aware of issues relating to aging. These include journal writing, life histories/autobiographical work, and creative representations of life experience such as video diaries, photographs, and artwork.

Of course, having outlined the contours of the narrative maps of the young athletes in our study, and made a number of suggestions as to how and why these maps might be changed, we fully acknowledge the difficulties of doing so. Changing their visions of what the future holds and expanding their narrative resources given their current sense of embodiment within a culture that stereotypes aging as a process of bodily decline is no easy task. Indeed, some might find our suggestions for intervention to be hopelessly naïve and unworkable. However, given the potential constraints that their current narrative maps put on their visions of aging, the vulnerable position this places them in as their bodies age, and the manner in which this may 
make them complicit in ageist ideologies, this issue should be a source of concern for all those involved with young athletes. As Tulle-Winton (2000) reminds us, "The task of critical gerontology and sociology therefore ought to be to imagine ways of being old that defy dominant narratives of old age and look for spaces of resistance where they are least expected" (p. 80). With this in mind, we suggest that the embodied world of young athletes deserves greater attention in the field of social gerontology in the future.

${ }^{1}$ At this point, it is important to note that it is not our intention to criticize the messages relating to a 'healthy lifestyle' advocated by the degree program, or to suggest that individuals should follow an inactive life course. Rather, our purpose is to shed light on the limiting and at times contradictory nature of this narrative map. For example, given that the disciplined body experiences its gravest crisis in the loss of control, what happens if the formula of "exercise now, and you'll benefit later" fails? In such instances, what other resources does this particular narrative map offer the young athletes in terms of aging meaningfully?

\section{Acknowledgements}

We wish to thank the two reviewers for their insightful and supportive comments on an earlier draft of this article.

\section{References}

Adams-Price, C., Henley, T., \& Hale, M. (1998). Phenomenology and the meaning of ageing for young and old adults. The International Journal of Psychosocial Gerontology, 47, 263-277.

Age Concern. (1990). Information factsheet. London: Age Concern.

Altpeter, M. (2003). Making aging 'real' for undergraduates. Educational Gerontology, 29, 739-757.

Anderson, S., Duddleston, A., Lancaster, B., \& Martin, C. (2001). Older selves and future ageing: Exploring healthy ageing. Edinburgh: Health Education Board for Scotland.

Birren, J. (2001). Foreword. In G. Kenyon, P. Clarke, \& B. De Vries (Eds.), Narrative gerontology, theory, research and practice (pp. vii-ix). New York: Springer.

Birren, J., Kenyon, G., Ruth, J., Schroots, J., \& Svensson, T. (Eds.). (1996). Aging and biography New York: Springer.

Blumer, H. (1969). Symbolic interactionism: Perspective and method. Englewood Cliffs, NJ: Prentice-Hall.

Bordo, S. (1993). Unbearable weight: Feminism, western culture, and the body. Berkley: University of California Press.

Brewer, B. W., Van Raalte, J., \& Linder, D. (1993). Athletic identity: Hercules' muscle or Achilles heel? International Journal of Sport Psychology, 24, 237-254.

British Gas. (1991). The British gas report on attitudes to ageing. London: British Gas. 
Bruner, J. (1990). Acts of meaning. Cambridge, MA: Harvard University.

Butler, J. (1990). Gender trouble. New York: Routledge.

Butler, J. (1993). Bodies that matter. London: Routledge.

Connell, R. (1995). Masculinities. Oxford: Polity Press.

Cortazzi, M. (1993). Narrative analysis. London: Falmer Press.

Crossley, M. L. (2000). Introducing narrative psychology: Self, trauma and the construction of meaning. Buckingham: Open University Press.

Eichberg, H. (2000). Life cycle sports: On movement culture and ageing. In J. Hansen, \& N. Nielsen (Eds.), Sports, Body and Health (pp. 89-104). Odense: Odense University Press.

Faircloth, C. (Ed.). (2003). Aging bodies New York: Altamira Press.

Featherstone, M., \& Hepworth, M. (1991). The mask of ageing and the post-modern life course. In M. Featherstone, M. Hepworth, \& B. Turner (Eds.), The body (pp. 371-389). London: Sage.

Featherstone, M., \& Hepworth, M. (1995). Images of positive aging: A case study of Retirement Choice magazine. InM. Featherstone, \& A.Wernick (Eds.), Images of aging (pp. 29-47). London: Routledge.

Fennell, V. (1994). Meanings of ageing in a southern town. In N. Sault (Ed.), Many mirrors: Body image and social relations (pp. 155-174). Rutgers: The State University.

Frank, A. (1991). For a sociology of the body: An analytical review. In M. Featherstone, M. Hepworth, \& B. Turner (Eds.), The body (pp. 36-102). London: Sage.

Frank, A. (1995). The wounded storyteller. Chicago: Chicago University Press.

Freeman, M. (2003). When the story's over, narrative foreclosure and the possibility of selfrenewal. In M. Andrews, S. Sclatter, C. Squire, \& A. Treader (Eds.), Lines of narrative (pp. 81-91). London: Routledge.

Gare, A. (2001). Narratives and the ethics and politics of environmentalism: The transformative power of stories. Theory and Science, 2, 1-17.

Garfinkel, H. (1967). Studies in ethnomethodology. Englewood Cliffs, NJ: Prentice-Hall.

Gergen, K. (1999). An invitation to social construction. London: Sage.

Gergen, K. (2001). Social construction in context. London: Sage.

Gergen, K. J. (1994). Realities and relationships. London: Harvard University Press.

Glense, C., \& Peshkin, A. (1992). Becoming qualitative researchers: An introduction. White Plains, NY: Longman.

Goffman, I. (1956). The presentation of self in everyday life. Harmondsworth: Penguin Books.

Gubrium, J., \& Holstein, J. (1998). Narrative practice and the coherence of personal stories. The Sociological Quarterly, 39, 163-187. 
Gubrium, J., Holstein, J., \& Buckholdt, D. (1994). Constructing the life course. New York: General Hall.

Hockey, J., \& James, A. (2003). Social identities across the life course. London: Palgrave Macmillan.

Holstein, J., \& Gubrium, J. (2000). The self we live by. New York: Oxford University Press.

Hyde, V., \& Gibbs, I. (1993). A very special relationship: Granddaughter's perceptions of grandmothers. Ageing and Society, 13, 83-96.

Langellier, K. (2001). 'You're marked': Breast cancer, tattoo, and the narrative performance of identity. In J. Brockmier, \& D. Carbaugh (Eds.), Narrative and identity (pp. 145-184).

Amsterdam: John Benjamins.

Lavalle, D., Grove, J., \& Ford, I. (1998). The experience of loss in sport. In J. Harvey (Ed.),

Perspectives on loss: A sourcebook (pp. 241-252).

Washington, DC: Taylor \& Francis.

Laz, C. (1998). Act your age. Sociological Forum, 13, 85-113.

Laz, C. (2003). Age embodied. Journal of Aging Studies, 17, 503-519.

Lieblich, A., Tuval-Mashiach, R., \& Zilber, T. (1998). Narrative research: Reading, analysis, and interpretation. London: Sage.

Linde, C. (1993). Life stories. New York: Oxford University Press.

Markus, H., \& Nurius, P. (1986). Possible selves. American Psychologist, 41, 954-969.

McAdams, D. (1993). The stories we live by: Personal myths and the making of the self. New York: William Morrow.

McLeod, J. (1997). Narrative and psychotherapy. London: Sage.

Miller, P. (1994). Narrative practices: Their role in socialisation and self-construction. In U. Neisser, \& R. Fivush (Eds.), The remembering self

(pp. 158-179). Cambridge: Cambridge University Press.

Mishler, E. (1999). Storylines: Craft artists' narratives of identity. Massachusetts: Harvard University Press.

Murray, M. (1999). The stories nature of health and illness. In M. Murray, \& K. Chamberlain (Eds.), Qualitative health psychology (pp. 47-63).

London: Sage.

Murray, M. (2003). Narrative psychology. In J. Smith (Ed.), Qualitative psychology (pp. 111-131). London: Sage.

Neikrug, S. (2003). Worrying about frightening old age. Aging and Mental Health, 7, 326-333. 
Newman, S., Faux, R., \& Larimer, B. (1997). Children's views on aging: Their attitudes and values. The Gerontologist, 37, 412-417.

Öberg, P. (2003). Images versus experience of the aging body. In C. Faircloth (Ed.), Aging bodies: Images and everyday experiences (pp. 103-139). Walnut Creek: Altamira Press.

O'Hanlon, A., \& Coleman, P. (2000). Testing the general attitudes to ageing scale among UK community living adults. Proceedings of the British Psychological Society, 8, 41.

O'Hanlon, A., \& Coleman, P. (2003). The general attitudes to ageing scale: Further validation of a new measure. Proceedings of the British Psychological Society, 11, 84.

Phoenix, C., Faulkner, G., \& Sparkes, A. (2005). Athletic identity and self-ageing: The dilemma of exclusivity. Psychology of Sport and Exercise, 6, 335-347.

Polkinghorne, D. (1995). Narrative configuration in qualitative analysis. In J. Hatch, \& R. Wisniewski (Eds.), Life history and narrative (pp. 5-24). London Falmer Press.

Pollner, M., \& Stein, S. (1996). Narrative mapping of social worlds: The voice of experience in alcoholics anonymous. Symbolic Interaction, 19, 203-223.

Riessman, C. (1993). Narrative analysis. London: Sage.

Riessman, C. (2002). Analysis of personal narratives. In J. Gubrium, \& J. Holstein (Eds.), Handbook of interview research (pp. 695-710). London: Sage.

Rich, E. (2004). Exploring teachers' biographies and perceptions of girls' participation in physical education. European Physical Education Review, 10, 215-240.

Ruth, J., \& Kenyon, G. (1996). Biography in adult development and aging. In J. Birren, G. Kenyon, J. Ruth, J. Schroots, \& T. Svensson (Eds.), Aging and biography (pp. 1-21). New York: Springer.

Schutz, A. (1970). On phenomenology and social relations. Chicago: University of Chicago Press.

Scott, T., Minichiello, V., \& Browning, C. (1998). Secondary school students knowledge of and attitudes towards older people: Does an education intervention programme make a difference? Ageing and Society, 18, 167-184.

Somers, M. (1994). The narrative constitution of identity: A relational and network approach. Theory and Society, 23, 605-649.

Sparkes, A. (1996). The fatal flaw: A narrative of the fragile body-self. Qualitative Inquiry, 2, 463-494.

Sparkes, A. (1998). Athletic identity: An Achilles' heel to the survival of self. Qualitative Health Research, 8, 644-664.

Sparkes, A. (2003a). From performance to impairment: A patchwork of embodied memories. In J. Evans, B. Davies, \& J. Wright (Eds.), Body knowledge and control (pp. 157-172). London: Routledge.

Sparkes, A. (2003b). Bodies, identities, selves: Autoethnographic fragments and reflections. In J. Denison, \& P. Markula (Eds.), "Moving writing": Crafting movement and sport research (pp. 51-76). New York: Peter Lang. 
Sparkes, A. (2004). Bodies, narratives, selves, and autobiography: The example of Lance Armstrong. Journal of Sport and Social Issues, 28, 397-428.

Tulle-Winton, E. (2000). Old bodies. In P. Hancock, B. Hughes, K. Patterson, R. Russell, E. TulleWinton, \& M. Tyler (Eds.), The body, culture and society (pp. 64-83). Buckingham: Open University Press.

Twigg, J. (2004). The body, gender, and age: Feminist insights in social gerontology. Journal of Aging Studies, 18, 59-73.

West, C., \& Zimmerman, D. (1987). Doing gender. Gender and Society, 1, 125-151.

Wolcott, H. (1994). Transforming qualitative data. London: Sage. 